\title{
On the utilization and development of solar energy in Tibet
}

\author{
Wenya Wang ${ }^{\text {a }}$ \\ Tibet Autonomous Region Energy Research Demonstration Center, Lasa 850000 China
}

\begin{abstract}
In order to better promote the application demonstration of clean energy such as solar energy, wind energy and geothermal energy in Tibet, scientifically develop and make rational use of new energy such as photovoltaic, photothermal, geothermal and wind power, optimize the energy supply structure, improve the guarantee capacity of energy use, and form a comprehensive energy system dominated by clean energy and complemented by other energy. This paper mainly discusses the importance, application and development of solar energy in Tibetan people's life by discussing the utilization of photoelectric and light and heat.
\end{abstract}

Keywords: Solar energy utilization; Photoelectric utilization; Photothermal utilization

\section{Introduction}

In 2021, the Arctic witnessed a high temperature of $48^{\circ} \mathrm{C}$, and the coldest Antarctic on earth measured an extreme high temperature of nearly $20^{\circ} \mathrm{C}$. In the past 50 years, the average temperature on the Antarctic Peninsula has increased by $3{ }^{\circ} \mathrm{C}$, glaciers have melted and sea level has risen, A series of chain reactions caused by climate change cry to us that the greenhouse effect caused by a large amount of carbon dioxide emitted by the combustion of fossil fuels is gradually destroying the earth's ecological environment on which people depend. However, people's demand for energy is still growing, and a large number of fossil energy is about to be consumed. Renewable energy dominated by solar energy, wind energy, hydropower, biomass energy and tidal energy accounts for an increasing proportion in the energy consumption structure. In the utilization of clean energy, due to the inexhaustible and wide distribution of solar energy, its development and utilization are more and more favored by people [1]. In order to cope with the surge of greenhouse gas emissions, China has also put forward the goal of "achieving carbon peak and carbon neutralization", saving energy and reducing carbon, reducing pollution and reducing carbon. As the "third pole of the world", the ecological environment of the Qinghai Tibet Plateau has attracted much national attention. Tibet is located on the Qinghai Tibet Plateau, with an average altitude of more than 4000 meters. The atmosphere is thin and clean, with high transparency, low latitude, strong ultraviolet rays and long sunshine time. Nature has endowed these characteristics with convenient conditions for the development and utilization of solar energy resources. According to relevant data, the main characteristics of the distribution of solar energy resources in China are: the high-value center and low-value center of solar energy are located in the area of $22 \sim 35^{\circ}$ north latitude. The Qinghai Tibet Plateau is the middle and west of high-value. Therefore, it can be said that Tibet is the most abundant area of solar energy in China. At the same time, according to the data provided by China natural resources database (China Institute of Natural Geographical Sciences and resources), the solar energy resources in Lhasa, Tibet: the annual total solar radiation value is as high as $745561 \mathrm{~J} /$ $\mathrm{cm}^{2}$ (1998 data), which is very close to the theoretical solar radiation (solar constant $=1353 \mathrm{~kW} / \mathrm{m}^{2}$ ) derived from solar energy, and the sunshine time is as long as 3007.8 hours, The sunshine rate over the years is as high as $69 \%$, the sky is clear and less cloudy, the solar radiation acceptance is good, and it is stable all year round.

With the continuous improvement of people's living standards, the requirements for living and living environment are becoming higher and higher. To create a comfortable environment, it is inevitable to consume energy. With the development of society, the depletion of non renewable resources and the destruction of ecological environment have been caused, which makes the contradiction between global social development and environmental protection more and more prominent. In this context, a new energy revolution with the concept of energy conservation, environmental protection and sustainable development is rising all over the world. As a renewable and clean energy, solar energy has attracted more and more attention all over the world in the process of seeking the sustainable development of human society. China is rich in solar energy resources. According to statistics, the total amount of solar radiation received by China's land every year is equivalent to $2.4 \times 1012 \mathrm{t}$ standard coal, the annual average daily radiation in most areas is more than $4 \mathrm{kWh} /\left(\mathrm{m}^{2} \cdot \mathrm{d}\right)$, and the annual radiation in more than $2 / 3$ areas in China is more than $5.02 \times 106 \mathrm{~kJ} / \mathrm{m} 2$, the annual sunshine hours are more

a 853969982@qq.com 
than $2000 \mathrm{~h}$, and even more than $3000 \mathrm{~h}$ in some areas in Northwest China. Therefore, the development and utilization of solar energy in China will create good social, environmental and economic benefits.

\section{Distribution of solar energy resources in Tibet}

Tibet is located in the southwest border of China. Its land area is second only to Xinjiang. The climate is generally cold and dry in the northwest and warm and humid in the southeast. In the distribution of solar energy resources in China, the total solar radiation in Western Tibet belongs to class I area [2], and the solar energy resources are the most abundant. The annual sunshine time is about $2600 \sim$ $3400 \mathrm{~h}$, and the total annual solar radiation is about 6680 $\sim 8400 \mathrm{MJ} / \mathrm{m}^{2}$. The total solar radiation in southeastern Tibet belongs to class II area, with abundant solar energy resources, and the annual sunshine time is about $3000 \sim$ $3200 \mathrm{~h}$, The total annual solar radiation is about $5852 \sim$ $6680 \mathrm{MJ} / \mathrm{m}^{2}$. Lhasa, known as "sunshine city", has an annual average sunshine duration of about $3005 \mathrm{~h}$ and an annual total solar radiation of about $8160 \mathrm{MJ} / \mathrm{m}^{2}$. On the whole, Tibet is extremely rich in solar energy resources.

\section{Utilization of solar energy resources in Tibet}

At first, Tibet used solar energy in a more traditional way, mostly burning cow dung, new firewood and other fires for cooking and heating, as well as building houses facing the north and the south. Since the 1950s, China began to develop and utilize solar energy and renewable energy. After the 1990s, the solar energy industry began to enter the stage of rapid development ${ }^{[3]}$. With the national laws and regulations on renewable energy and the encouragement and support policies for solar energy development, Tibet introduced advanced technology, talent training and assistance projects at home and abroad, Gradually improve the utilization of solar energy, which is mainly divided into photoelectric utilization and photothermal utilization.

\subsection{Photoelectric utilization}

Because of its special geographical location and climate environment, Tibet has unique advantages in power generation. Among them, the annual irradiance of the best inclined plane for photovoltaic power generation in the Middle East of Xigaze City, the northwest of Shannan City, the south central part of Lhasa city and the west of Ali is as high as $2500 \mathrm{kWh} / \mathrm{m} 2$, which is 1.13 times that of the best inclined plane for photovoltaic power generation in Tibet, and the amount of technology development is about 2 billion $\mathrm{kW}$. The utilization of solar energy in Tibet is similar to that in most parts of China. It is mainly divided into photovoltaic and photothermal power. Farmers and herdsmen in remote villages still use biomass energy such as cow dung as the main combustion energy. The Institute of Geophysics of Tibet University has tested and prepared a dye-sensitized solar cell with a mixed natural pigment of walnut and Arnebia, which has an efficiency of $8.2 \%^{[4]}$. At present, it has not been put into production.

(a) Photovoltaic power generation

Tibet's photovoltaic power generation mainly uses silicon-based polysilicon photovoltaic modules as power generation units. Under the irradiation of sunlight, the internal semiconductor materials generate potential difference through photovoltaic effect, which converts light energy into electric energy and directly uses solar energy. According to the power demand, under the distribution of the controller, part of it is transmitted to the inverter, and the DC generated by the photovoltaic module is converted into AC under the action of the inverter for use by users; The excess power is stored in the battery. After the battery is full, the remaining power will be connected to the Internet. This often refers to the photovoltaic grid connected power generation system, which can be equipped with or without the battery. Independent photovoltaic systems are often used in remote villages in Naqu and Ali. Due to the high average altitude compared with other cities, the early construction is extremely sparsely populated and pastoral areas, and the power supply cost of the State Grid is very high. The independent photovoltaic system is generally installed on the user's side, and the generated electric energy is not connected to the Internet. Part of it is used by the user, and the rest is stored in the battery. However, households in pastoral areas often like to configure the user's system, and the power generation basically ensures the daily power consumption of the user's family. It is small and easy to carry and install.

Some enterprises and institutions have built and installed monocrystalline silicon solar panels and amorphous silicon thin film solar cells for research and demonstration. Due to the relatively poor cost performance and other factors, they have not been promoted on a large scale in Tibet. Individual machines have built photovoltaic smart microgrid and Microgrid platform for research and analysis.

In 1990, the first photovoltaic power station in Tibet (with an installed capacity of $10 \mathrm{kWp}$ and an independent photovoltaic power station, which has been expanded, at least $60 \mathrm{kWp}$ at present) was built in Ali Geji county. Up to now, it still supplies power to the office building of the county government and the dormitory of the county Party committee, and the operation is in good condition. In 2011, Longyuan Tibet Yangbajing photovoltaic power station (installed capacity $10 \mathrm{MWp}$ ), the first large-scale grid connected photovoltaic power station in Tibet, was successfully connected to the grid. In 2021, a 50MW "photovoltaic + energy storage" photovoltaic power station was built in Xigaze, Tibet, and successfully connected to the grid for power generation, which is the largest "photovoltaic + energy storage" investment project in Tibet.

(b) Photothermal power generation

Photothermal power generation is an indirect solar power generation method that converts light energy into heat energy and then into electric energy ${ }^{[5]}$. It mainly includes slot linear focus thermal power generation system, 
Stirling butterfly thermal power generation system, tower solar thermal power generation system and Fresnel thermal power generation system. Disadvantages: low efficiency and high cost. At present, it can only be used in special occasions on a small scale, and large-scale utilization is economically uneconomical compared with other ways of power generation.

As the first solar thermal power generation project to be started in Tibet, the 50MW trough type solar thermal power station in Gongga County, Tibet is still under preparation as of 2018 .

\subsection{Photothermal utilization}

The use of light and heat in Tibet is mostly used for daily heating and domestic water. The main utilization methods include the construction of solar collector, solar stove and solar house.

The solar heating system has the following characteristics: a) the solar collector can operate under pressure, the heat pipe is specially treated, and the normal operation of the system will not be affected when the glass pipe is damaged. The design of collector and support is reasonable, and can play the role of roof insulation layer. b) The constant temperature and pressure device is adopted to ensure the temperature and pressure of water at the water terminal, and the automatic circulating insulation device realizes the instant opening and heating of hot water. c) It is used together with the auxiliary heat source low-temperature heat pump, so that the heating system is not affected by season, day and night and weather. When the system cannot meet the heat energy needs of users in cloudy and rainy days and at night, the insufficient part is provided by auxiliary energy to ensure the normal operation of the heating system in the absence of solar radiation. d) Energy saving and consumption reduction. Building energy consumption accounts for nearly $1 / 3$ of the total social terminal energy consumption in China. The perfect combination of solar heating system and buildings can greatly reduce conventional energy consumption and promote the development of society towards "low input, low energy consumption, low pollution and high output". e) Green environmental protection. As a clean renewable energy, solar energy has no environmental pollution.

(a) Solar collector is a device that absorbs solar radiant energy and transfers the generated heat energy to heat transfer working medium ${ }^{[6]}$. It is the core component of water heater, mainly including vacuum tube, flat plate type, trough type collector and so on. Vacuum tube collectors are mostly distributed in domestic water of household users, and most of them use vacuum tube collectors for collective heating of urban households and institutions (companies, etc.); The second is flat plate collector, which is mostly used for government collective housing or scientific research analysis; Trough collectors exist on the research platforms of individual enterprises and institutions. Individual families use solar air conditioning.

(b) Solar cooker is a device for cooking food. It has the functions of boiling water, cooking, frying, frying and frying. It is easy to operate. It mostly exists in farmers and herdsmen's families, and some urban users are also using it to facilitate them to cook and boil water.

(c) Sunshine houses have basically spread to all regions and families in Tibet. Solar houses are divided into active and passive. Solar houses in Tibet are mostly corridors and courtyards with glass structure. Individual government enterprises and institutions use solar collectors to obtain solar heat and send it to indoor heating through heat distribution system for pilot research.

(d) The sun in Tibet is often directly used for drying dried meat and preserved fruits, and solar dryers are rarely used. (e) The working principle of solar greenhouse is greenhouse effect, also known as artificial greenhouse, commonly known as "Greenhouse". It is distributed in Lhasa, Shigatse and Ali, and is mostly used to grow vegetables, melons and fruits.

\section{Prospect of solar energy resources in Tibet}

As a green and pollution-free renewable energy, although the energy density of solar energy is low and intermittent and random, it does not affect the development and utilization of solar energy in Tibet. After years of development and accumulation, the solar energy utilization technology tends to be more mature and perfect, the utilization methods are more diverse, and the application fields are more and more broad. According to the development and utilization of clean energy and the realization of the zero carbon goal during the 14th Five Year Plan period, Tibet will continue to increase investment in the solar energy industry. Energy storage and heat storage are important parts of the development of solar photovoltaic and photothermal respectively. With the technological innovation, the service life will gradually grow, the storage cost will continue to decline, and the phenomenon of solar light and heat abandonment will be slowly removed.

\section{Conclusion}

In the development and utilization of renewable energy in Tibet, the development and utilization of solar energy resources is only one of them. Relevant utilization technologies need to be improved and upgraded, and the development and utilization of other new energy resources is also developing rapidly. Promote the integration of energy resources, coupling multiple energy resources with complementary advantages, and optimize the structure of energy supply and consumption.

\section{Acknowledgments}

Study on the change of power consumption structure in xumai Township, Nimu County (XZ202101ZR0037G) 


\section{References}

1. Yan Yunfei, Zhang Zhien, Zhang Zhang Zhang, Dai Changlin. Solar energy utilization technology and its application [J]. Journal of solar energy, 2012,33 (S1)

2. Luo Yunjun, he Zinian, Wang Changgui. Solar energy utilization technology (Second Edition) [M]. Beijing: Chemical Industry Press, 2013

3. Wu Juanxiu. Research on laws and regulations of solar energy development and utilization [J]. Chinese and foreign entrepreneurs, 2016, (23)

4. Nusan, tsogawangm, et al. Preparation of natural pigment dye-sensitized solar cells [J]. Materials guide, 2013,27 (S2)

5. Cai Shijie. Research status and development prospect of solar energy utilization technology $[\mathrm{J}]$. China high tech, 2018, (21)

6. Chen Deming, Xu Gang. Overview of solar thermal utilization technology [J]. Physics, 2007, (11) 